\title{
LD Body in Epitrochliar Lymphnode in a Bone Marrow and Splenic Aspiration Negative Indian Kala Azar
}

\author{
RATAN DAS GUPTA, ${ }^{1}$ APARNA DAS, ${ }^{1}$ TITU MI AH, $^{1}$ MOHAMMAD ASHI KI MRAN KHAN, ${ }^{2}$ MUNTASI R HASNAI N, ${ }^{3}$ \\ BIШALALAM, ${ }^{4}$ AHAMEDUL KABI R ${ }^{1}$
}

\begin{abstract}
:
Kala Azar is a parasitic disease cause by Leishmania Donovani, transmitted by sand fly phlebotomus. Lymphadenopathy is not a common presentation in Indian Kala azar. We present an adult male from endemic zone of kalaazar presented with epitrochlear lymphadenopathy and hepato-splenomegaly and diagnosed by presence $L D$ in lymphnode biopsy.
\end{abstract}

Keyword: Kala Azar, Lymphadenopathy, Leishmania Donovani (LD) body, Bangladesh

\section{Introduction:}

Leishmaniases are caused by 20 species of Leishmania (L) and transmitted by 30 species of sandfly. The sandfly bites humans at night, primarily at twilight. Bangladesh is one of the endemic zone of Kala-a-zar along with India, Nepal. ${ }^{1}$ After malaria eradication programme(1961-1970) Kala-Azar almost disappeared but at present kalaazar is a re-emerging disease and major public health problem in Bangladesh. ${ }^{2}$ Kala aza cases are reported from 45 districs including 139 upazilas of Bangladesh. More than 10,000 people newly infected in each year. ${ }^{2}$ Kala Azar usually presented with fever, weight loss hepatosplenomegaly and progressive leucopenia. ${ }^{3}$ Lymphadenopathy is rare presentation in Indian kalaazar, first case reported from Bangladesh in $1986 .{ }^{4}$ We report here a patient who presented with fever, hepatosplenomegaly from endemic zone but without LD body in bone marrow and splenic puncture, but ultimately was diagnosed by presence of LD body in epitrochliar lymph node biopsy .

\section{Case report:}

A 45 years old man from endemic zone of Kala-Azar (Tangail) admitted in Dhaka medical college hospital with the complaints of fever, cough and weight loss for last three months. Fever was initially low-grade, gradually become high grade for last one month without any periodicity, not responding to conventional antipyretics. He also complained of cough with scanty sputum and two episodes of hemoptysis. He noticed mark weight loss for last 3 months.
He had no history of contact with any patient with tuberculosis. He received several courses of antibiotics but failed to respond.

He was wasted, moderately anaemic on general examination. His weight was $38 \mathrm{~kg}$, pulse 94/min , blood pressure 90/60 $\mathrm{mm}$ of $\mathrm{Hg}$, temp $101^{0} \mathrm{~F}$. His both epitrochliar lymph nodes were palpable, nontender, discrete, freely mobile and firm in consistency. His liver was palpable $7 \mathrm{~cm}$ from right subcostal margin, non-tender, firm in consistency, smooth surface with sharp margin. Spleen also palpable $20 \mathrm{~cm}$ from left subcostal margin which was non-tender and firm in consistency. His other systemic examinations were unremarkable.

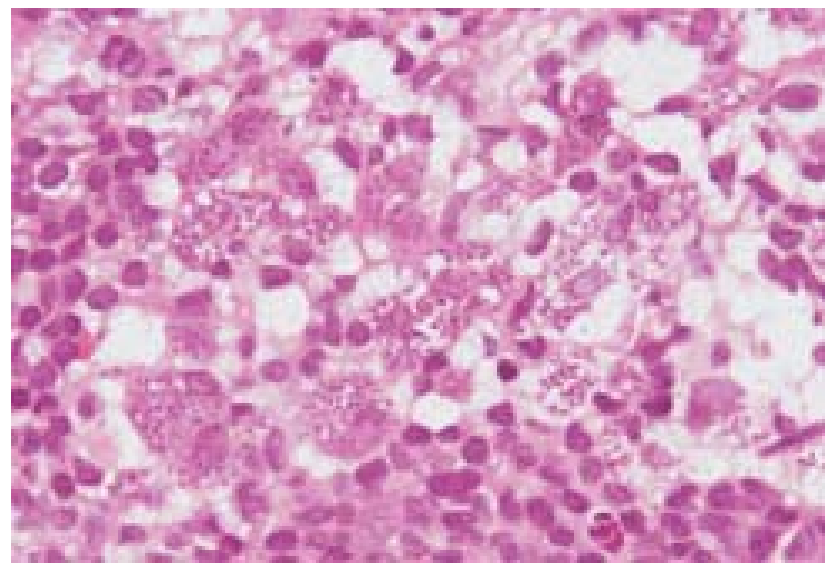

Fig.-1: LD body in lymph node biopsy

1. Assistant Professor, Department of Medicine, Dhaka Medical College

2. Post-graduate Trainee, Department of Medicine, Dhaka Medical College

3. FCPS (Medicine) course student, Dhaka Medical College

4. Associate Professor, Department of Medicine, Dhaka Medical College.

Correspondence: Dr. Mohammad Ashik Imran Khan, Post Graduate Trainee, Dhaka Medical College Hospital, Dhaka. E mail: ashikmrn@yahoo.com 
Laboratory report revealed haemoglobin 8gm/dl, ESR-120 $\mathrm{mm}$ in 1 st hour, total count of WBC- $3.5 \times 10^{9} / \mathrm{L}$ with Neutrophils 55\%, Lymphocytes 38\%, Monocytes 05\%, Eosinophils $02 \%$. Platelet count 200x10 $\%$ L, peripheral blood film showed normocytic normochromic anaemia with thrombocytopenia, did not show malarial parasites. Chest $\mathrm{X}$-ray was normal and Mantoux test was negative, ultrasonogram of abdomen revealed Hepatosplenomegaly. Endoscopy of upper GIT revealed normal study. ICT KalaAzar negative, bone barrow aspiration showed active marrow with Plasmacytosis (15\%) no parasites . Splenic puncture revealed no LD body. Serum protein electrophoresis showed polyclonal gammopathy. VDRL was non-reactive. Finally lymphnode biopsy was performed which revealed LD body within histocytes and in the stoma, thus giving the ultimate diagnosis of Kala Azar.

\section{Discussion:}

Kala-azar is caused by L. donovani complex, which includes L. donovani, L. infantum and L. chagasi. It is characterised by prolonged irregular fever, hepato-splenomegaly, lymphadenopathy and progressive anaemia. 4 Lymphadenopathy in Indian Kala-Azar is not a very common finding but presence of LD body in lymphnode even rarer. ${ }^{6}$ Sengupta and Chatterjee in 1961 first reported primary lymphadenopathy in Indian Kala Azar proved by biopsy. ${ }^{7}$ Talukdar et al. in 1987 reported another case of lymphadenopathy in a 11 year old boy suffering from Indian Kala-Azar from Bihar. ${ }^{8}$ Other, few reports of Indian KalaAzar with lymphadenopathy in adults have also been reported. In 1998 a case of lymphadenopathy in Kala-Azar in 13 years old boy reported from Nepal. ${ }^{9-11}$ To best of our knowledge, only two cases have been reported where lymphadenopathy was present in association with kala azar in Bangladesh first in 1986 and then in 2008. 5,9,12

Diagnosis of visceral Leishmaniasis can be often difficult if dependence is solely on finding LD body, In our patients case, though the clinical scenario was clearly indicating a diagnosis but tissue or serological diagnosis which is essential was lacking. The ICT based rk-39 antibody test has rapidly gained popularity in Bangladesh with a 100\% sensitivity and 93\%-98\% specificity. ${ }^{13,14}$ WHO describes demonstration of Leishmania Donovani is the most specific test for the diagnosis of kala- azar. This is done by examination of bone marrow or splenic aspirate as the aspirates from these sites contain the highest concentration of the parasites. Though hese tests are considered as the "gold standard" for the diagnosis of kala-azar they failed provode a diagnosis in our patient. ${ }^{15} \mathrm{~A}$ new antigen based test agglutination test (KATEX) identifies the antigens in Kala-azar patients' urine. ${ }^{16}$
PCR based diagnostic tools are highly sensitive and specific but the cost has kept it away from the poor countries who are the victim of the disease. Recent advances have allowed the Nested PCR to be performed from blood (buffy coat) instead of splenic or bone marrow aspirates. ${ }^{17}$ the possible causes of not finding the LD body is that only in few percentage of cases it is missed and we did not go for tissue culture or any PCR based method which are more specific as diagnostic tools.

In conclusion it can be said that when encountered with the above scenario, diagnosis can be elusive as differentials like tuberculosis, deep fungal infection also come forward. High index of suspicion and a bit of luck is essential for diagnosis. Advanced diagnostic facilities need to be established if our goal of elimination is to be realize in future.

\section{Conflict of Interest: None}

\section{References:}

1. Desjeux P. Human leishmaniasis: epidemiology and Public health aspects. Wrld Hlth Stat Q 1992 ;45: 267-75

2. Status of kala-azar in Bangladesh, Bhutan, India and Nepal: A regional review update searo.who.int/LinkFiles/ Kala_azar_kala-status 2008 Web page feb 2009

3. Bern C, Hightower A W, Chowdhury R, Ali M, et al. Risk factors for kala-azar in Bangladesh. Emerging Infectious Disease 2005 ;11( 5): 655-662

4. Agrawal S, Rai M and Sundar S. Management of visceral leishmaniasis: Indian perspective. J Post grad Med. 2005 51; 53-57

5. Chowhury A.H.M, Islam N. Unusual features of kalaazarA case Report. Bangladesh Med. Res. Counc. 1986; xii (2): 99-104

6. Sengupta PC, Chatterjee A. Lymphadenopathy in a case of Indian Kal-Azar. J Indian Med Assoc 1961; 36: 21-22

7. Sengupta PC, Mukherjee AM. Lymphadenopathy in Indian Kala-Azar and dermal leishmaniasis. Indian JPathol Bacteriol 1968; 11: 172-178

8. Talukdar B, Kanwar A, Saini L, Singh T, Chauhan S. Lymphadenopathy in Indian Kala-Azar. Indian Pediatr.1987; 24: $1043-1045$

9. KuldeepSingh,RupaSingh ,S.c.Parija*, Lymphadenopathy in a Child with Indian Kala-Azar in Dharan, Nepal: Indian Pediatrics 1998;36:1125-1126

10. Nandy A, Choudhary AB. Lymphadenopathy in Indian Kala-Azar. Ann Trop Med Parasitol1984; 28: 331-332

11. Sameer Gulati, HP Paljor, Sanjay Pandit, Richa Jindal, Kala Azar without splenomegaly, Ann Trop Med Public Health 2009;2:57-60 
12. MdShafiqul Bari, Mirza AzizulHoque, KFM Ayaz, Afsana Begum, RubinaYasmin, Md BillalAlam, HAM Nazmul Ahasan, Lymphadenopathy - An Unusual Clinical Feature of Kala-azar. Journal of medicine: 2008,; 9( 2):108-109

13. Sundar S, Reed SG, Singh VP, Kumar PCK, Murrary HW. Rapid accurate field diagnosis of visceral leishmaniasis. Lancet 1998;351:563-5

14. Bern C, Jha SN, Joshi AB, Thakur GD, Bista MB. Use of the recombinant $\mathrm{k} 39$ dipstick test and the direct agglutination test in a setting endemic for visceral leishmaniasis in Nepal. Am J Trop Med Hyg 2000;63:153-7
15. Attar ZJ, Chance ML, el-Safi S, Carney J, Azazy A, ElHadi M, et al. Latex agglutination test for detection of urinary antigens in visceral leishmaniasis. Acta Trop 2001;78:11-6

16. Kala-azar elimination in the SEA Region - Training module.Available at : www.searo.who.int/LinkFiles/ Kala_azar_SEAR_Training.pdf

17. Katakura K, Kawazu SI, Naya T, Nagakura K et.al. Diagnosis of Kala-Azar by Nested PCR Based on Amplification of the Leishmania Mini-Exon Gene. J Clinic Micro, 1998;8: 21732177. 